\title{
Transporte Público da Região Metropolitana de Campinas
}

Public Transport of the Metropolitan Region of Campinas

Transporte Público de la Región Metropolitana de Campinas

Geise Brizotti Pasquotto

Professora Doutora, Brasil geisebp@gmail.com

Ricardo Alexandre da Silva
Professor Doutor, UNIP, Brasil
ricardo.silva1@docente.unip.br

Alice Ramos da Silva

Discente, UNIP, Brasil aliceramos949@gmail.com

Ana Carolina Luques

Discente, UNIP, Brasil luques.ana@hotmail.com

\section{Bianca Cristina Rabonato Pereira \\ Discente, UNIP, Brasil bianca.rabonato@hotmail.com}

\section{Efrain Mateus da Costa Gadelha \\ Discente, UNIP, Brasil efraimmateusgadelha@gmail.com}

Gislaine da Silva Ovando da Motta

Discente, UNIP, Brasil gislainedamotta@gmail.com

Victor Hugo Buzim Fantini

Discente, UNIP, Brasil vb.fantini@gmail.com 


\title{
RESUMO
}

A pesquisa apresentada se constitui da análise e caracterização da rede de transporte público na Região Metropolitana de Campinas (RMC) por meio da elaboração de gráficos, tabelas e mapas embasados nos dados fornecidos pela Empresa Metropolitana de Transportes Urbanos (EMTU), que realiza o gerenciamento das frotas de ônibus na região. $\mathrm{O}$ trabalho objetiva a compreensão do cenário atual da mobilidade intermunicipal discorrendo sobre as relações de influência entre as cidades, o efeito causado na migração pendular e qualifica a quantidade de frotas disponíveis enquanto ao atendimento da demanda diária. Ainda acerca dessas relações é evidenciada a necessidade de uma redistribuição das frotas em relação as linhas atendidas em determinados horários, aumento da quantidade de linhas para que todas as cidades possam dispor de conexão com outras cidades da RMC, criação de um corredor metropolitano para diminuição de trajetos e revisão de tarifas em desacordo com a distância do trajeto percorrido.

PALAVRAS-CHAVE: Transporte Público. RMC. EMTU.

\begin{abstract}
The research is constituted by the analysis and characterization of the public transport network in the Metropolitan Region of Campinas (RMC). The analysis is done through the elaboration of charts, tables and maps based on the data provided by the company that manages the bus fleets in the region, the Metropolitan Urban Transport Company (EMTU). The work aims at a complete understanding of the current situation of mobility between cities, discussing the relations of influence, in order to determine the pendularity and qualifies the fleets available at the same time as the daily demand. Moreover, this relations evidence the need to redistribute the fleets according to the lines served during particular periods along the day, to increase the number of lines so that all cities can be connect with other cities of the RMC, creating a metropolitan corridor for the reduction of routes and revision of tariffs in disregard to the distance of the route traveled.
\end{abstract}

KEY-WORDS: Public Transport. RMC. EMTU.

\section{RESUMEN}

La investigación presentada se constituye de análisis y características de las redes de transporte público en la Región Metropolitana de Campinas (RMC). El análisis se da a través de la elaboración de gráficos, tablas y mapas basados en los datos obtenidos por la empresa que hace la gerencia de las flotas de buses en la región, la empresa de Transportes Urbanos (EMTU). El trabajo tiene como objetivo la comprensión del escenario actual de la movilidad intermunicipal explicando las relaciones de influencia entre las ciudades, el efecto que se da con la migración pendular y califica la cantidad de flotas disponibles en base a la atención de la demanda diaria. Sobre esas relaciones es evidenciada la necesidad de una redistribución de las flotas en relación a las líneas atendidas en determinados horarios, aumento de la cantidad de líneas para que todas las ciudades puedan tener conexión con otras ciudades de la RMC, creación de una pista metropolitana para la disminución de trayectos y revisión de tarifas en desacuerdo con la distancia del trayecto recorrido.

PALABRAS-CLAVE: Transporte Público. RMC. EMTU. 


\section{O CONCEITO DE MOBILIDADE URBANA, ACESSIBILIDADE E TRANSPORTE}

Nas últimas décadas o Brasil passou por transformações significativas na estrutura de suas cidades. Novos assentamentos humanos resultaram em uma expansão contínua e espraiada da malha urbana, geralmente caracterizada pela segmentação e diferenciação social e econômica, pela periferização e pela conurbação. Essas novas áreas, distanciadas do centro da cidade são geralmente inadequadas ao adensamento excessivo e contam com poucos equipamentos sociais e infraestrutura escassa (CUNHA et al, 2004).

Entende-se que mobilidade é a possibilidade de um indivíduo movimentar-se pelo espaço, sendo esta possibilidade influenciada por atributos (tais como renda, condição física e outros) e pela disponibilidade de meios de deslocamento compatíveis. $\mathrm{O}$ tema da mobilidade se relaciona diretamente com a acessibilidade, que pode ser definida como "a facilidade [...] para deslocarse e participar de uma atividade, como o trabalho, a educação, o lazer, etc, usando um modo de transporte." (ROSA, 2006, p. 13 apud ULIAN, 2008, p. 20). Devido a distância das periferias aos centros urbanos, onde se concentram as ofertas de trabalho, saúde, educação, cultura e lazer, é exigido dos indivíduos maiores esforços para se deslocarem de um local para o outro (ROSA, 2006). Pode-se afirmar, portanto, que "o crescimento da população urbana tem como consequência um aumento da necessidade por mobilidade" (CAMPOS, 2007, p. 06).

O Instituto de Pesquisas Econômicas Aplicadas (IPEA) divulgou dados evidenciando que em cidades com mais de 60 mil habitantes, $38 \%$ dos deslocamentos ainda são feitos a pé (BRASIL, 2012). Porém, a análise do tecido urbano demonstra que pelo modo espraiado que gradativamente essa malha aumenta, não existe proximidade urbana através de adensamento. Assim a grande quantidade de fluxo percorridos a pé é na realidade o efeito de um acesso restrito aos meios de transporte, seja pele elevado valor da tarifa ou pela insuficiência do atendimento da rede (SILVEIRA; COCCO, 2013). Como resultado, tais pessoas experimentam grande dificuldade em vivenciar plenamente o espaço urbano, os recursos e serviços que dele fazem parte na mesma intensidade que os indivíduos mais favorecidos, revelando a falta de acessibilidade.

Para Cass et al (2005, p. 549), a acessibilidade pode ser compreendida em quatro dimensões: financeira, física, organizacional e temporal. Em um cenário perfeito de acessibilidade, há a disponibilidade de um ponto de ônibus nas imediações, por onde passa uma linha que atenda ao desejo de deslocamento, por um preço atraente, com qualidade, pontualidade e dentre outros aspectos.

Com finalidade de garantir a mobilidade acessível em seus diferentes aspetos foi instaurada a Lei 13.683/18, que exige que os municípios com mais de 20 mil habitantes, e/ou integrantes de regiões metropolitanas, e/ou integrantes de áreas de especial interesse turístico, até abril de 2019 elaborem seus planos de mobilidade urbana, sob pena de ficarem impedidos de contratar recursos federais.

O trabalho apresentado busca caracterizar o sistema de mobilidade em vigência na região metropolitana de Campinas, com objetivo final de compreender pontos positivos e negativos. Por meio de revisão bibliográfica se faz compreensível a conceituação da mobilidade e o contexto histórico do recorte estudado. Por meio da elaboração de gráficos e mapas embasados 
nos dados fornecidos pela empresa que faz o gerenciamento e coordenação do transporte intermunicipal, é feita a análise do sistema atual e sua eficácia no atendimento da crescente demanda advinda do espraiamento da malha urbana caracterizando as viagens intermunicipais e compreendendo a relação intramunicipal da mobilidade.

\section{CONTEXTUALIZAÇÃO E DADOS DA REGIÃO METROPOLITANA DE CAMPINAS}

A Região Metropolitana de Campinas foi criada em 2000 e possui 20 municípios: Americana, Artur Nogueira, Campinas, Cosmópolis, Engenheiro Coelho, Holambra, Hortolândia, Indaiatuba, Itatiba, Jaguariúna, Monte Mor, Morungaba ${ }^{1}$, Nova Odessa, Paulínia, Pedreira, Santa Bárbara d'Oeste, Santo Antônio de Posse, Sumaré, Valinhos e Vinhedo. "É a segunda maior região metropolitana do Estado de São Paulo em população, com mais de 3,1 milhões de habitantes, de acordo com estimativa do Instituto Brasileiro de Geografia e Estatística (IBGE) para 2017, e gerou 8,92\% do Produto Interno Bruto (PIB) estadual em 2015" (EMPLASA, 2018, online).

De acordo com a prefeitura de Campinas (2014) a expansão urbana observada na região a partir dos anos 70 foi marcada pela crescente horizontalização e periferização dos espaços urbanizados, intensificando o processo de articulação de Campinas com os municípios limítrofes. Esse padrão de expansão urbana consolidou-se principalmente na região Sudoeste da cidade, na direção dos municípios de Sumaré, Hortolândia, Monte-Mor e ao sul em Indaiatuba. A expansão da cidade ao longo da via Anhanguera se deu principalmente em função do padrão de instalação industrial do processo de interiorização do desenvolvimento, que privilegiou os grandes eixos rodoviários regionais. Este movimento de periferização da região foi reforçado pela abertura do Aeroporto Nacional de Viracopos, pela implantação do Distrito Industrial de Campinas e pela construção de vários conjuntos habitacionais ao longo da via Anhanguera, existe hoje na região um eixo contínuo de ocupação ao longo da rodovia decorrente de um período de migração para a região em busca de oportunidades nas indústrias que se instalaram no interior de São Paulo, configurando uma mancha linear que se estende de Vinhedo até Americana, articulando vigorosamente a economia, o mercado de trabalho e a rotina deste conjunto de municípios. Segundo Alves (2007), os sistemas rodoviário e ferroviário foram grandes estruturadores e influenciadores dos espaços urbanos. "Assim como foi a estrada de ferro, a rodovia também influencia novos vetores de crescimento, propiciando inclusive movimentos de conurbação" (ALVES, 2007, p. 116). Atualmente a região é uma grande mancha conurbada, no período das três últimas décadas, a população da área da atual RMC passou de 680.826 habitantes para 2.333.230 ao todo (ALVES, 2007, p. 96).

\section{TRANSPORTE PÚBLICO NA RMC}

O sistema metropolitano de transporte sobre pneus é gerenciado pela Empresa Metropolitana de Transportes Urbanos (EMTU) e operado por empresas privadas. A EMTU não opera os ônibus, mas coordena e regulamenta todo o serviço prestado por concessionárias que efetivamente

\footnotetext{
${ }^{1}$ Morungaba foi inserida na RMC através da Lei Complementar no 1.234/14
} 
dispõem os ônibus nas linhas para realizarem o transporte (EMTU, 2018). O gráfico abaixo indica a quantidade de viagens diárias que partem das cidades listadas. É notável a influência da cidade de Campinas em sua região metropolitana. Verifica-se que das 5.133 viagens que acontecem todos os dias, 1.917 partem de Campinas. Em comparação com o gráfico 2, que ilustra os horários das viagens, entende-se que a maior parte destas estão relacionadas ao movimento de migração pendular, em que as pessoas migram para cidades próximas para estudar ou trabalhar e retornam para suas cidades ao final do expediente. Importante observar que a ausência de viagens com origem em Morungaba é procedente da falta de transporte intermunicipal na cidade.

Gráfico 1: Quantidade de viagens por dia útil

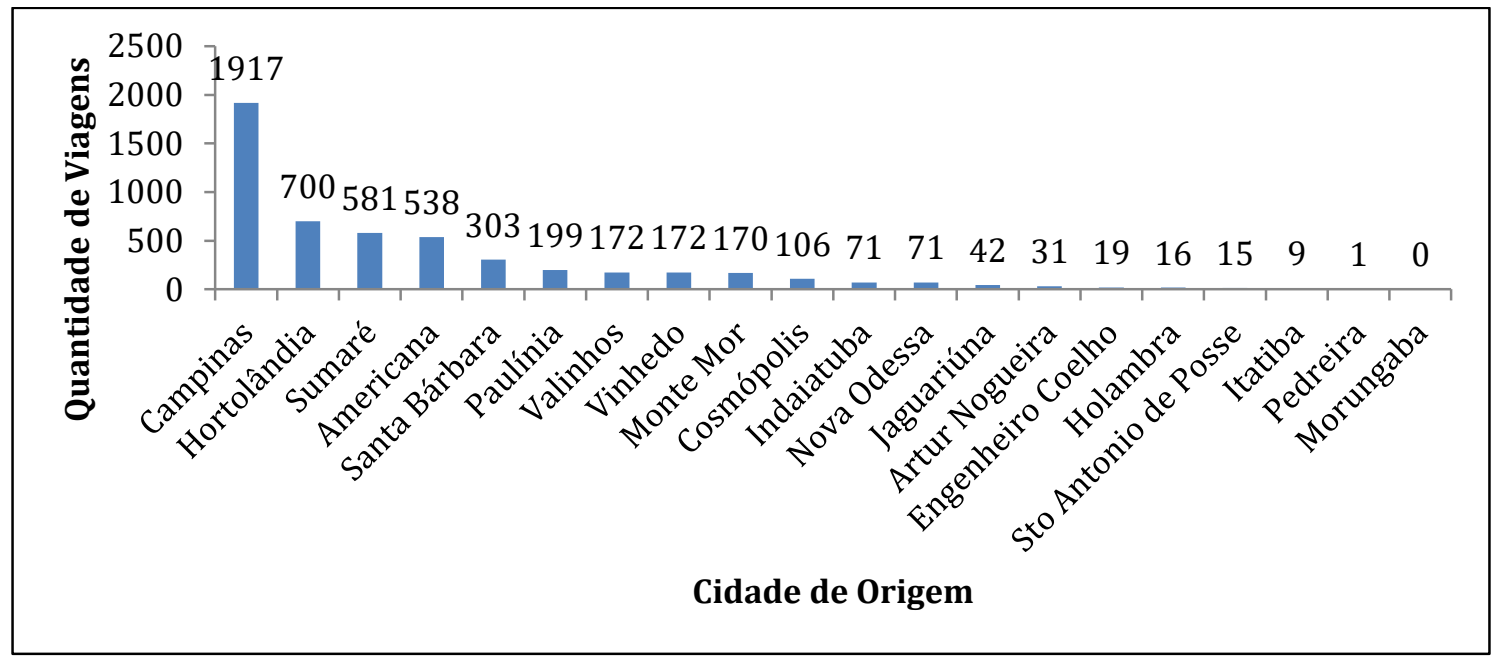

Fonte: Elaborado pelos autores a partir de informações disponibilizadas pela EMTU (2018).

Gráfico 2: Quantidade de viagens por hora na RMC

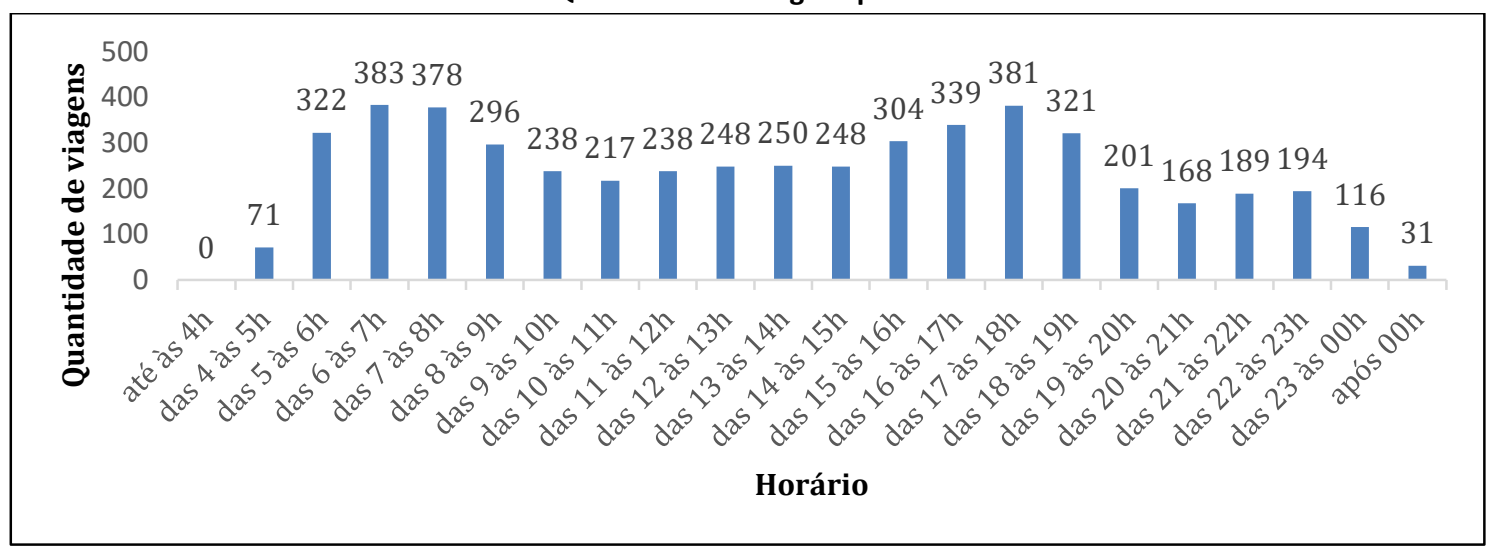

Fonte: Elaborado pelos autores a partir de informações disponibilizadas pela EMTU (2018).

\section{CARACTERÍSTICAS DOS DESLOCAMENTOS PENDULARES NA RMC}

A cidade de Campinas é o centro da RMC, portanto, é o destino da maior parte dos habitantes da região que se movimentam em suas rotinas de trabalho. De acordo com Caiado (2006), a 
relação entre mobilidade e segregação se estabelece na medida em que os segmentos populacionais de menor poder político e econômico, ao residirem em áreas específicas do território intrametropolitano (onde é restrito o acesso à infraestrutura urbana e aos serviços básicos), muitas vezes precisam recorrer a grandes deslocamentos diários para o atendimento das demandas por trabalho, educação, saúde, etc. Pode-se dizer que, como ocorre em outras regiões, a metropolização de Campinas sintetiza, ao mesmo tempo, as tendências do capitalismo e da industrialização moderna e a herança do atraso estrutural da economia e da sociedade brasileira (GONÇALVES et al., 2002).

De acordo com Pereira (2008), por estar próxima da Região Metropolitana de São Paulo (RMSP), o impulso que a economia da região de Campinas recebeu durante a interiorização do desenvolvimento econômico do Estado de São Paulo - proveniente, principalmente, da desconcentração industrial da RMSP. Pires (2007, p. 15) ressalta que:

A expansão metropolitana de Campinas tem início nesse período, a partir dos anos 1970, impulsionada pelo processo de interiorização da indústria no Estado de São Paulo, atraindo população e investimentos. Essa nova dinâmica urbana e regional imprimiu novas características às funções das cidades, especialmente do pólo regional.

Assim, Gonçalves et al. (2002), afirma que apesar da RMC estar dentro do raio de influência imediata da RMSP, seu rápido crescimento econômico e populacional conseguiu estruturar uma área de influência própria, trazendo expansão e modernização para região.

Essa influência da cidade de Campinas sobre a região pode ser traduzida em maior oferta de emprego, em 2003, dos 872.409 postos de trabalho ocupados em toda Região Metropolitana de Campinas, $28,8 \%$ (251.416) se concentram no recorte de Centro Metropolitano delimitado pelo estudo de Pires (2007).

Apenas a Zona OD de №1, que é apontada pela Emplasa como o centro da cidade de Campinas, concentra $5,8 \%$ dos postos de trabalho ocupados da região. Posteriormente, a zona correspondente ao centro de Americana, concentra 4,9\%. Todas as demais zonas possuem menos do que $3,4 \%$ dos postos de trabalho ocupados da região, o que indica quão elevada é a concentração de empregos na sua região central. Somente a área do Centro Metropolitano proposto por Pires (2007), por sua vez, concentra cerca de $29 \%$ dos postos de trabalho.

A partir da análise dessas informações, é possível mensurar o grau de concentração e dispersão dos postos de trabalho pelo território da metrópole. De acordo com Caiado et al. (2006, p. 17)

\begin{abstract}
A ocorrência de viagens entre os eixos de expansão definidos está relacionada principalmente ao papel funcional que pode ser atribuído aos diferentes segmentos espaciais que os compõem. O centro metropolitano, principal ponto de concentração de empregos, principalmente no que se refere às atividades de comércio e serviço (setor que mais emprega na região), evidentemente aparece como produtor do maior número de viagens pendulares.
\end{abstract}

Em sua tese, Pires (2007) também chama atenção para o peso do Centro Metropolitano no padrão de deslocamentos pendulares da região, e destaca esse centro como o local de maior concentração de empregos e de convergência do sistema de transporte coletivo municipal e metropolitano. Segundo a autora, o Centro Metropolitano é o principal destino para trabalho e 
para estudo, exceto para as viagens por motivo "trabalho" com origem no vetor AmericanaSanta Bárbara d'Oeste (Americana, Santa Bárbara d'Oeste e Nova Odessa), cujas viagens externas mais significativas são com o vetor Anhanguera-Sumaré, e para as viagens por motivo "estudo" com origem no vetor Anhanguera-Vinhedo (vetor 6), onde o Centro Metropolitano é o segundo destino, sendo o primeiro o vetor Campinas-Paulínia (onde se localiza a Unicamp e a Puc-Campinas) (PIRES, 2007, p.55).

\section{RELAÇÕES INTRAURBANAS DA MOBILIDADE}

Em relação à mobilidade intermunicipal, é necessário também compreender o sistema de transporte público dentro de cada cidade, e também, a forma como é feita a prestação dos serviços executados pela prefeitura no que diz respeito ao atendimento à população, em especial, na esfera do transporte. Em relação ao transporte público municipal, verificou-se que somente as cidades de Engenheiro Coelho, Morungaba e Santo Antônio de Posse não fornecem este serviço à população, nas demais cidades este serviço é prestado por empresas terceirizadas, contratadas por meio de licitação ou por veículos próprios da prefeitura como é o caso de Valinhos. Uma particularidade é que na cidade de Santo Antônio de Posse existe apenas 01 ônibus que faz o transporte para lugares específicos da cidade voltados aos trabalhadores.

No quesito do atendimento às camadas mais frágeis da população, destacam-se os seguintes pontos: i) os universitários que estudam em outras cidades, cujos cursos não sejam disponíveis na cidade onde residem, possuem um serviço de auxílio de subsídio em relação ao transporte, que vão desde reembolso parcial do valor gasto, até reembolso total ou uso de fretados da prefeitura; ii) o transporte escolar dentro de cada munícipio, é garantido à população de diferentes formas, gratuito, feito pela própria prefeitura ou por empresa terceirizada (Santo Antonio de Posse, Holambra, Americana, Paulínia, Morungaba, Jaguariúna, Valinhos, Arthur Nogueira, Cosmópolis, Indaiatuba, Nova Odessa), somente para alunos que moram em área rural ou subúrbio (Engenheiro Coelho, Itatiba, Pedreira), passe livre (Sta Barbara D’Oeste, Valinhos, Sumaré) e passagem com desconto (Campinas, Hortolândia); iii) o transporte médico para pacientes que dependem de tratamentos específicos em outras cidades, é um serviço fornecido por todas as cidades da RMC. Este transporte é realizado através de vans, microônibus, ambulâncias e transporte especial (dependendo da gravidade do paciente) totalmente gratuito; existe também na cidade de Valinhos um programa chamado TFD (Tratamento Fora do Domicílio) que é uma lei atendida pelo SUS onde o paciente pode solicitar através da prefeitura um reembolso do valor gasto no transporte particular do paciente.

Importante destacar também o transporte acessível nas cidades. Segundo informações da EMTU as pessoas com deficiência física o transporte público oferece o Serviço Especial Conveniado - SEC a atual frota em operação, que não é própria, mas, constituída de operadores credenciados à Secretaria dos Transportes Metropolitanos (STM) conta com 450 veículos, adaptados e adequados ao transporte de passageiros cadeirantes e não cadeirantes. O Serviço faz atendimento do tipo "porta a porta" para cerca de 4300 crianças e adolescentes (e acompanhantes), entre suas casas e as 865 escolas ou instituições 
conveniadas/credenciadas com a Secretaria de Educação do Estado de São Paulo na Região Metropolitana de São Paulo e Região Metropolitana de Campinas.

\section{ARRANJOS POPULACIONAS NA RMC}

De acordo com o Instituto Brasileiro de Geografia e Estatística (OMI, 2018), o conceito de arranjo populacional "é o agrupamento de dois ou mais municípios onde há uma forte integração populacional devido aos movimentos pendulares para trabalho ou estudo, ou devido à contiguidade entre as manchas urbanizadas principais". O Observatório Metropolitano de Indicadores (OMI, 2018) da AGEMCAMP estudou um quadro com os arranjos populacionais ocorridos na Região Metropolitana de Campinas (RMC), baseado no estudo do Instituto Brasileiro de Geografia e Estatística (IBGE, 2016): "Arranjos Populacionais e Concentrações Urbanas do Brasil". Observa-se a existência de três arranjos populacionais na Região Metropolitana de Campinas: i) Campinas, ii) Americana-Santa Bárbara d'Oeste e iii) Artur Nogueira (Figura 1). O arranjo de Campinas agrega o maior fluxo interno de indivíduos que trabalham e/ou estudam em outros municípios (158.896 pessoas realizando essa migração pendular por estudos e trabalho).

Paulínia é o município que tem o maior número de indivíduos que circula em função do trabalho e/ou estudo dentro desse arranjo e no geral 32,38\% da população (26.595 pessoas) realiza deslocamentos em função de trabalho e/ou estudos. Em relação ao índice de integração (quantidade de pessoas que trabalham e/ou estudam nos municípios do arranjo, dividido pelo número de pessoas que trabalham e/ou estudam nos próprios municípios), o "arranjo Americana-Santa Bárbara d'Oeste" resulta o maior valor de integração. Ou seja, um índice de 0,33 . Em termos municipais, as cidades de Hortolândia e Paulínia registram os maiores índices de integração: 0,55. 
Figura 1: Mapa RMC - Proporção dos migrantes em movimento pendular e polos de trabalho

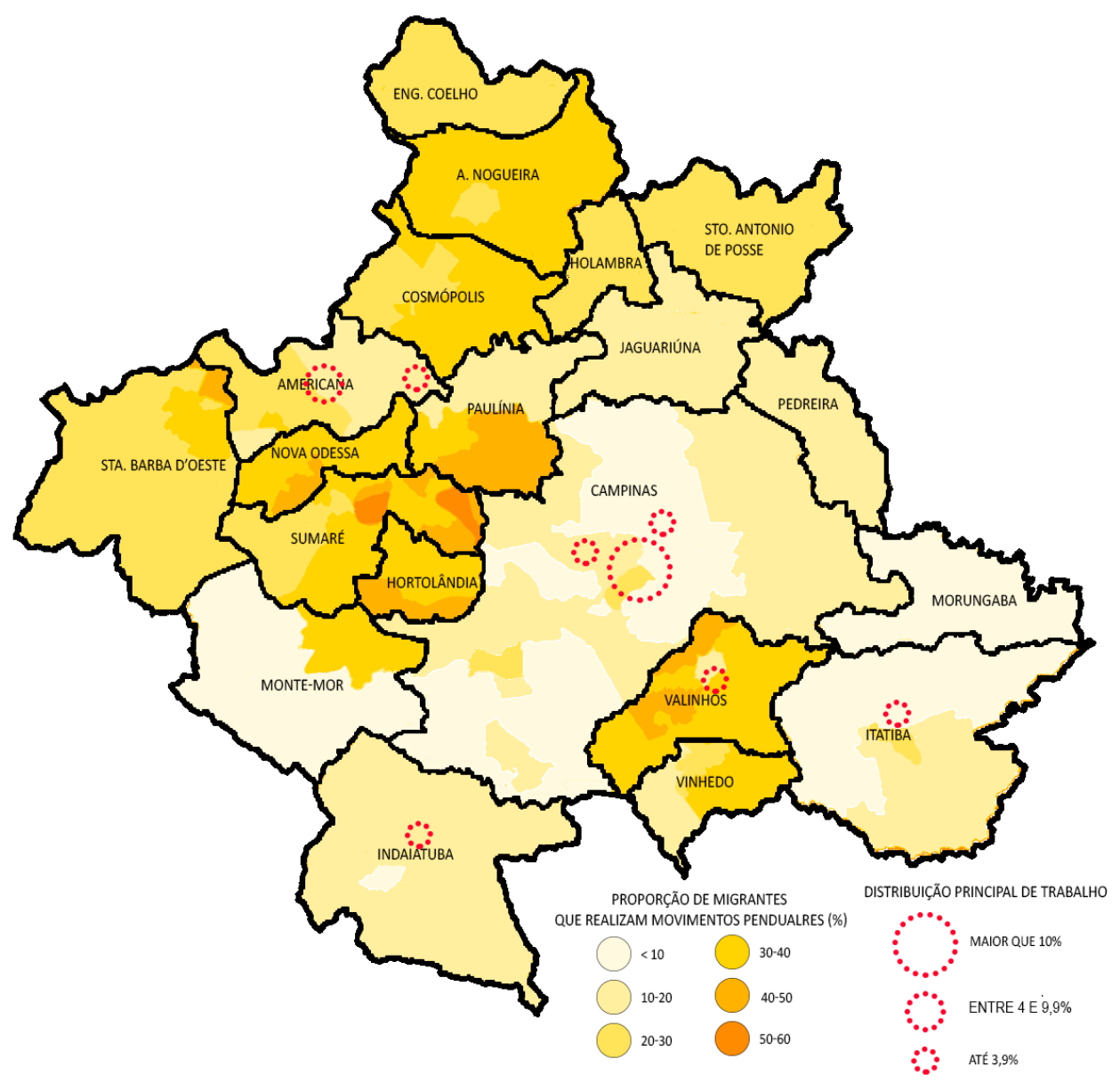

Fonte: Elaborado pelos autores com base em dados fornecidos pelo Censo Demográfico IBGE 2010 e Emplasa, 2018.

\section{7. ÍNDICES RELATIVOS AOS DESLOCAMENTOS E FRAGILIDADES}

A pesquisa de origem e destino domiciliar (O/D) desenvolvida em 2003 pela Secretaria dos Transportes Metropolitanos de São Paulo na Região Metropolitana de Campinas, foi a primeira pesquisa desta natureza que possibilitou a observação de alguns fatos relevantes provenientes dos deslocamentos intermunicipais na região:

- Fluxos entre a RMC e a área externa: Diariamente são realizadas na RMC um total de 4.746.347 viagens. Comparativamente à pesquisa OD realizada em 2003 houve um acréscimo de $32 \%$. 0 índice de mobilidade total passou de 1,58 viagens diárias por habitante, em 2003, para 1,73 viagens diárias por habitante, em 2011. Do total de viagens, 107.020 são viagens externas, com origem ou destino fora da RMC. (SMT - Secretaria dos Transportes Metropolitanos de São Paulo 2012);

- Tipo de Transporte: Em 2003, 64,16\% das viagens eram realizadas por modo motorizado. Em 2011, das 4,75 milhões de viagens realizadas diariamente na RMC, 3,44 milhões (72,6\%) eram realizadas por modo motorizado. Ou seja, ocorreu um crescimento de viagens motorizadas. 0 
mesmo ocorreu com as viagens no modo individual. Em 2003, 35,7\% das viagens foram realizadas por este modo, e em $2011,43,66 \%$, o que sugere que o aumento da mobilidade se deve especialmente às viagens em automóveis. Além disso, uma parcela significativa das viagens na RMC se faz a pé $(25,1 \%)$, mas o modo mais utilizado é o automóvel $(38,5 \%)$. O ônibus municipal é responsável por 14,2\% e o Ônibus intermunicipal por 3,4\% das viagens. Somadas as modalidades de transporte por ônibus (municipal, intermunicipal, fretado, escolar, executivo), sua participação chega a $28,9 \%$, valendo também destacar os 5,6\% das viagens realizadas pelo transporte fretado (SMT 2012);

- Causa das viagens: A Pesquisa O/D constatou a intensa característica pendular das viagens entre os municípios da RMC. Observou-se que os principais motivos das viagens na RMC, desconsiderando o período do dia e as viagens motivo residência, são o trabalho $(45,5 \%)$ e a educação (21,2\%).

A partir dos dados levantados anteriormente, nota-se a ausência de alguns fatores que poderiam maximizar, facilitar e agilizar a mobilidade por meio da rede de transportes públicos. Para Alves (2007, p.143), primeiramente não há um sistema concebido para operar de forma integralizada, sendo formada por um conjunto de subsistemas atuando de forma autônoma. A integração física e tarifária é ausente, se restringindo ao subsistema municipal de Campinas e apesar dos altos investimentos feitos em estudos e projetos, ainda não se dispõe de um plano integrado para o transporte público de passageiros, e também, a Região Metropolitana de Campinas não possui, como a maioria das regiões metropolitanas brasileiras, um sistema tarifário unificado para o transporte coletivo por ônibus, sendo que cada município detém o poder de definir a tarifa para sua área e a STM/ EMTU define a tarifa para as linhas intermunicipais.

O sistema tarifário vigente para os ônibus intermunicipais da RMC, sob gestão da STM/EMTU, é o quilométrico com a fixação da tarifa diferenciada por linha ou trecho de linha, em função das distâncias percorridas, no entanto observa-se que há exceções, como por exemplo o caso de Holambra a Campinas, que em uma rota onde são percorridos $20 \mathrm{~km}$ a tarifa chega a um valor superior a 10 reais, enquanto outras rotas com o dobro de distância têm valor inferior. Ademais, nos municípios da RMC não existem vias de tratamento preferencial para o transporte coletivo, assim como não constam, nos seus planos diretores, diretrizes para priorizá-los. Em Campinas, apenas o Corredor Amoreiras que faz a ligação do Terminal Ouro Verde na região Sudoeste com - Terminal Central, possui tratamento preferencial para o transporte coletivo com pista segregada.

Para fins de melhoria, há o projeto para o corredor metropolitano Biléo Soares (Corredor Noroeste) (Figura 2), que atenderá as cidades de Santa Bárbara D’Oeste, Americana, Nova Odessa, Sumaré, Hortolândia e Campinas, conforme ilustrado na imagem 1. Essa região representa $75 \%$ do fluxo regional diário da população que trabalha e se desloca pelos polos desenvolvidos ao longo da região (como Sumaré e Hortolândia no segmento de alta tecnologia, além de Campinas, que concentra os serviços regionais) (EMTU, 2018). No entanto, as obras apresentam atrasos de mais de 3 anos em alguns pontos, como o terminal de Americana, principalmente por conta de descumprimentos de contrato por parte da empresa contratada. A EMTU chegou a multar e rescindir o contrato, fazendo com que as obras atrasassem ainda mais, 
causando muitos transtornos para a população que sofre não apenas com a falta de um sistema viário eficaz, mas também com o fechamento de vias para a execução do novo corredor.

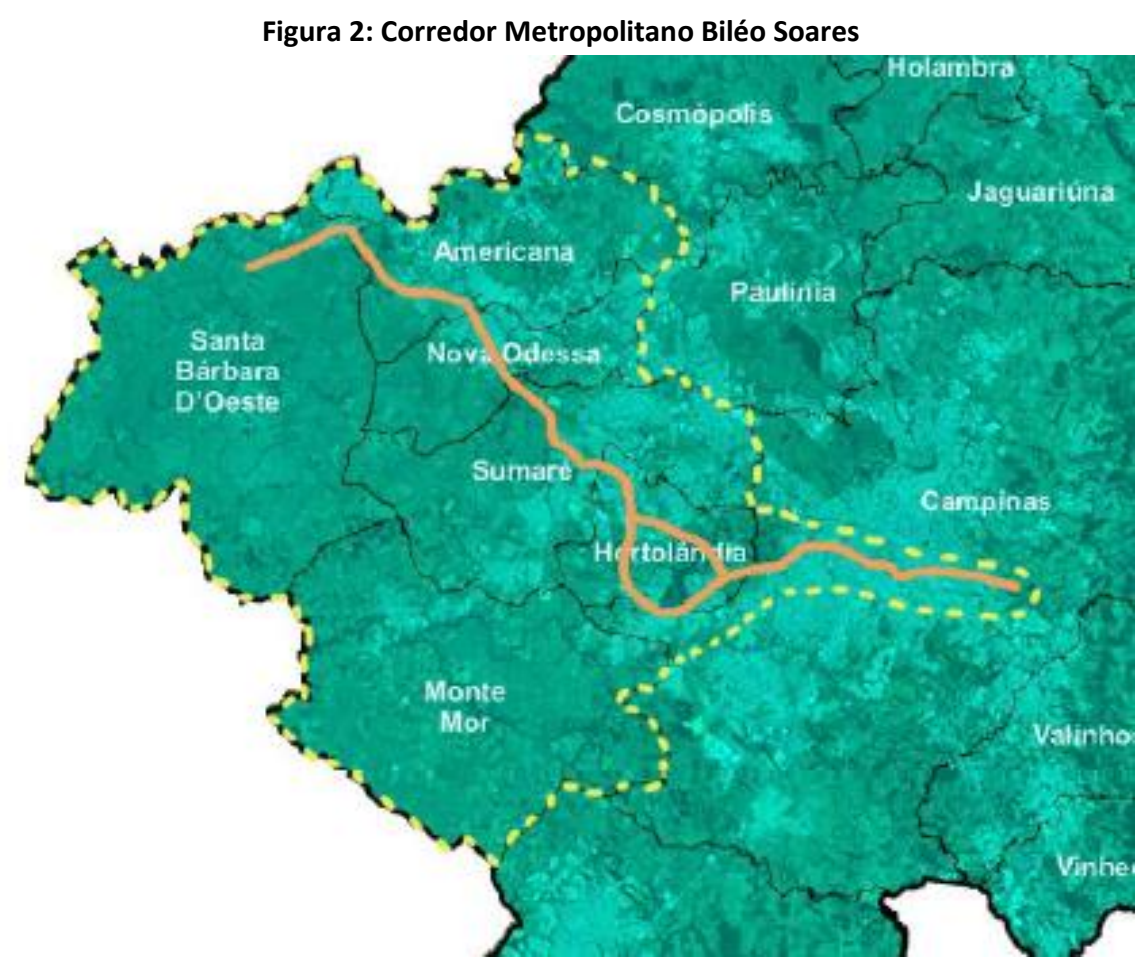

Fonte: Elaborado pelos autores com base em dados fornecidos pela EMTU (2018).

Outro ponto notório é que muitas cidades, pertencentes da região, não possuem linhas de ônibus interurbano para realizar ligação direta entre elas. Esse fato faz com que a viagem realizada pela população seja dividida por escalas feitas em outras cidades e consequentemente eleva-se o valor total e o tempo gasto no deslocamento. Pode-se analisar a relação das possíveis escalas realizadas entre as cidades sem conexão direta no Quadro 1. 
Quadro 1: Relação das linhas de transporte público interurbanas das cidades da RMC

\begin{tabular}{|c|c|c|c|c|c|c|c|c|c|c|c|c|c|c|c|c|c|c|c|c|}
\hline Partida/Destino & 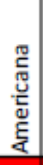 & 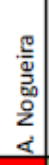 & 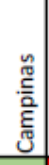 & 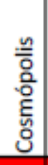 & 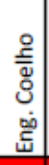 & $\begin{array}{l}\frac{0}{0} \\
\frac{0}{E} \\
\frac{\pi}{0} \\
\frac{0}{1}\end{array}$ & 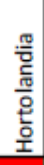 & 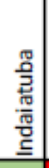 & 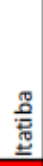 & 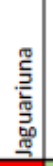 & 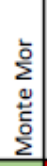 & 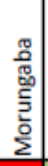 & 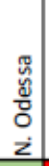 & 罢 & 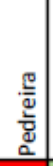 & 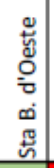 & 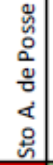 & 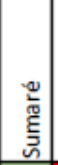 & 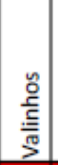 & $\begin{array}{l}\text { 움 } \\
\stackrel{0}{5} \\
5 \\
5\end{array}$ \\
\hline \multicolumn{21}{|l|}{ Americana } \\
\hline \multicolumn{21}{|l|}{ Artur Nogueira } \\
\hline \multicolumn{21}{|l|}{ Campinas } \\
\hline \multicolumn{21}{|l|}{ Cosmópolis } \\
\hline \multicolumn{21}{|l|}{ Engenheiro Coelho } \\
\hline \multicolumn{21}{|l|}{ Holambra } \\
\hline \multicolumn{21}{|l|}{ Hortolandia } \\
\hline \multicolumn{21}{|l|}{ Indaiatuba } \\
\hline \multicolumn{21}{|l|}{ Itatiba } \\
\hline \multicolumn{21}{|l|}{ Jaguariuna } \\
\hline \multicolumn{21}{|l|}{ Monte Mor } \\
\hline \multicolumn{21}{|l|}{ Morungaba } \\
\hline \multicolumn{21}{|l|}{ Nova Odessa } \\
\hline \multicolumn{21}{|l|}{ Paulínia } \\
\hline \multicolumn{21}{|l|}{ Pedreira } \\
\hline \multicolumn{21}{|l|}{ Sta. B. d'Oeste } \\
\hline \multicolumn{21}{|l|}{ Sto. A. de Posse } \\
\hline \multicolumn{21}{|l|}{ Sumaré } \\
\hline \multicolumn{21}{|l|}{ Valinhos } \\
\hline Vinhedo & & & & & & & & & & & & & & & & & & & & \\
\hline
\end{tabular}

Legenda

Cidades que não possuem conexão direta por transporte público

Cidades que possuem conexão direta por transporte público

Fonte: Elaborado pelos autores com base em dados fornecidos pela EMTU.

Conclui-se por meio da grande presença de células vermelhas no diagrama, que boa parte das cidades pertencentes a região metropolitana de Campinas não possui linhas diretas de ônibus para as demais cidades e que a maior presença de ônibus, (células verdes) como esperado, acontece no município de Campinas.

Muitos trajetos apresentam distâncias muito longas que poderiam ser feitas por outros percursos menores, cidades que ficam próximas ou até são vizinhas como Americana e Paulínia, mas não há existência de transporte público que vai de diretamente de uma a outra, então se uma pessoa residente em Americana precisar se locomover até Paulínia através do ônibus, precisará ir para Sumaré ou para Campinas para escalar sua viagem, aumentando o custo da viagem. Diferente de uma pessoa que reside em Engenheiro Coelho e precise se deslocar até Indaiatuba, o trajeto apresentaria uma longa distância por serem cidades que se localizam em extremos opostos norte e sul (Quadro 2). 
Quadro 2: Exemplo de cidades da RMC que não possuem ligação direta de transporte público e sugestão de trajeto $^{2}$

\begin{tabular}{|c|c|l|l|}
\hline \multicolumn{4}{|c|}{ Cidades sem Conexão Direta de Transporte Público } \\
\hline Origem/Destino & Destino/Origem & $\begin{array}{c}\text { Percurso Sugerido } \\
\text { (menor distância } \\
\text { percorrida) }\end{array}$ & Valor Total \\
\hline Americana & A. Nogueira & $\begin{array}{l}\text { Americana } \leftrightarrow \text { Campinas } \\
\leftrightarrow \text { A. Nogueira }\end{array}$ & RS $\quad 18,70$ \\
\hline Americana & Cosmópolis & $\begin{array}{l}\text { Americana } \leftrightarrow \text { Campinas } \\
\leftrightarrow \text { Cosmópolis }\end{array}$ & RS $\quad 16,95$ \\
\hline Americana & Eng. Coelho & $\begin{array}{l}\text { Americana } \leftrightarrow \text { Campinas } \\
\leftrightarrow \text { Artur Nogueira } \leftrightarrow \\
\text { Eng. Coelho }\end{array}$ & RS 23,60 \\
\hline
\end{tabular}

Fonte: Elaborado pelos autores com base em dados fornecidos pela EMTU.

A partir da análise também pode-se constatar que a maior parte das escalas é feita na cidade de Campinas devido essa ser a maior cidade da RMC, ser localizada no centro e possuir maior oferta de infraestrutura e equipamentos públicos, logo o maior número de linhas para as outras cidades da região. As escalas que não são necessariamente feitas em Campinas acontecem nas "sub-regiões", que são determinadas por grupos de cidades que realizam um movimento pendular frequente entre elas mesmas. Outro ponto crítico constatado foi que a cidade de Morungaba não possui conexão nenhuma com as demais cidades da RMC, por meio do transporte público, subentende-se que a população morungabense não se beneficia dos equipamentos e infraestrutura das demais cidades da região e que provavelmente a cidade tem mais relação com a cidade de Atibaia, pertencente a microrregião de Bragança Paulista.

\section{CONSIDERAÇÕES FINAIS}

Evidenciando a necessidade por transporte público adequado à demanda crescente, Campinas concentra a maior oferta de trabalho e educação, resultando em um movimento de migração pendular com notória intensidade. $O$ transporte público não oferece mobilidade adequada a população, tanto na esfera intermunicipal quanto internamente em cada cidade. No quesito interurbano, dependendo das cidades de origem e destino, a população precisa fazer escalas que não se enquadram na lógica da mobilidade contemporânea, prolongando o tempo de viagem e elevando o custo total. O problema existe não apenas em trajetos com destino a Campinas, mas também na interação entre cidades limítrofes que fazem parte de arranjos populacionais paralelos e que ocasionalmente têm valores de tarifa superiores aos de viagens com distâncias mais longas. Quando analisado o sistema intramunicipal, nota-se que ainda existem algumas cidades da região que não possuem transporte intra-urbano adequado, também gerando desconforto a população, que sofre com a falta de transporte público ou com a baixa qualidade do serviço prestado.

\footnotetext{
${ }^{2}$ A tabela completa identifica todos os percursos sugeridos em casos de cidades que não tem conexão direta no transporte intermunicipal. Para este artigo foi realizado um recorte ilustrando através de casos extremos a fragilidade apresentada.
} 
Além da falta de conexões diretas entre cidades que tem relação migratória e por vezes dividem limites, outro ponto de destaque é a falta de uma cobrança unificada para as pessoas que precisam se locomover por diferentes municipalidades com diferentes meios de cobrança.

Por meio da análise dos dados fornecidos, observa-se um aumento do número de viagens no horário de pico, fazendo com que as frotas disponíveis não sejam acessíveis em determinados períodos do dia, apesar de existirem veículos o suficiente para a demanda, não há organização e distribuição adequada das frotas. Por conta dessa ineficiência do sistema de transporte atual, houve um aumento significativo de deslocamentos realizados por meio de transporte individual motorizado entre os anos de 2003 e 2011. A conclusão da implantação do corredor metropolitano noroeste, que abrange cidades que representam $75 \%$ do fluxo migratório total da região, pode ser uma solução para melhorar a qualidade da mobilidade por meio da redução do tempo e do percurso das viagens pela melhor fluidez do trânsito. No entanto, os esforços de cada cidade individualmente serão necessários para que esse meio seja acessível para todos e não apenas aos que moram próximos do trajeto, fazendo com que haja mudanças efetivas na configuração atual dos deslocamentos.

\section{REFERÊNCIAS BIBLIOGRÁFICAS}

ALVES, M. A. S. Espacialidades, Escala e Complexidade dos Problemas Metropolitanos: 0 caso da Região Metropolitana de Campinas (RMC). Tese de Doutorado, Universidade Estadual de Campinas, Instituto de Economia. Campinas, 2007. Disponível em:

http://repositorio.unicamp.br/jspui/bitstream/REPOSIP/285419/1/Alves_MariaAbadiadaSilva_D.pdf> Acesso em: 17 mar 2018.

BRASIL. Instituto de Pesquisas Econômicas Aplicadas (Ipea). Notícias. Brasília, 2012. Disponível em: <http://www.ipea.gov.br/portal/index>. Acesso em: 17 mar 2018.

CAIADO, M. C. S.; PIRES, M. C. S. O verso e o reverso da dinâmica metropolitana: mobilidade populacional e estruturação socioespacial. In: ENCONTRO NACIONAL DE ESTUDOS POPULACIONAIS, 15., 2006, Caxambu. Anais... Belo Horizonte: ABEP, 2006.

CAMPINAS. Região Metropolitana: Campinas como sede da Região Metropolitana. Disponível em: < http://www.campinas.sp.gov.br/governo/seplama/plano-diretor-2006/doc/tr_rmc.pdf> Acesso em: 17 mar 2018.

CAMPOS, V. B. G. Uma visão da mobilidade urbana sustentável. 2007. Disponível em: <http://www.fetranspordocs.com.br/downloads/08umavisaodaMobilidadeUrbanaSustentavel.pdf>. Acesso em: 01 set 2018.

CASS, Noel; SHOVE, Elizabeth; URRY, John. Social exclusion, mobility and access. The Sociological Review. Volume 53, Issue 3, p. $539-555,2005$.

COELHO, C. S. O. Análise da Acessibilidade por Transporte Público Coletivo no Município de Campinas (Monografia). Departamento de Geografia - Instituto de Geociências da Universidade Estadual de Campinas, 2012.

CUNHA, J. M. P da; JAKOB, A. A. E.; HOGAN, D. J.; CARMO, R. L. A vulnerabilidade social no contexto metropolitano: - caso de Campinas. Disponível em: <http://www.nepo.unicamp.br/publicacoes/livros/vulnerabilidade/arquuivos/arquuivos/vulnerab_cap_5_pgs_143_ 168.pdf $>$. Acesso em: 01 set 2018.

EMPLASA, Empresa Paulista de Planejamento Metropolitano. Sobre a RMC. Disponível em: <https://www.emplasa.sp.gov.br/RMC>. Acesso em: 17 mar. 2018. 
EMTU, Empresa Metropolitana de Transporte Urbano. Itinerários e Tarifas Secretaria dos Transportes Metropolitanos - Governo do Estado de São Paulo. [Internet]. Disponível em: <http://www.emtu.sp.gov.br/emtu/itinerarios-etarifas.fss>. Acesso em: 17 mar 2018.

EMTU. Corredor Metropolitano Biléo Soares (Noroeste). Disponível em: <http://www.emtu.sp.gov.br/emtu/redesde-transporte/corredores-terminais/corredor-metropolitano-bileo-soares-noroeste.fss>. Acesso em: 17 mar 2018.

EMTU. Rede de Transportes. Disponível em: <http://www.emtu.sp.gov.br/emtu/redes-de-transporte/regular/o-quee-regular.fss>. Acesso em: 17 mar. 2018.

GONÇALVES, M. F.; SEMEGHINI, U. Uma metrópole singular. In: FONSECA, Rinaldo Barcia; DAVANZO, Áurea M. Q.; NEGREIROS, Rovena M. C. (Org.). Livro verde: desafios para a gestão da Região Metropolitana de Campinas. Campinas: IE/Unicamp, 2002.

IBGE, Instituto Brasileiro de Geografia e Estatística. Arranjos populacionais e concentrações urbanas no Brasil / IBGE, Coordenação de Geografia. - 2. ed. - Rio de Janeiro : IBGE, 2016. Disponível em: <https://biblioteca.ibge.gov.br/visualizacao/livros/liv99700.pdf>. Acesso em: 17 mar. 2018.

OMI, Observatório Metropolitano Indicadores da RMC. RMC: Arranjos Populacionais. Disponível em: <http://www.agemcamp.sp.gov.br/observatorio/index.php?option=com_content\&view=article\&id=528:rmcarranjos-populacionais\&catid=2: noticias\&Itemid=8>. Acesso em: 18 mar 2018.

PEREIRA, R. H. M. Processos socioespaciais, reestruturação urbana e deslocamentos pendulares na Região Metropolitana de Campinas / Rafael Henrique Moraes Pereira. - Campinas, SP : [s. n.], 2008.

PIRES, M. C. S. Morar na metrópole: expansão urbana e mercado imobiliário na Região Metropolitana de Campinas. Tese De Doutorado, Universidade de São Paulo - USP, 2007.

ROSA, S. J. Transporte e Exclusão Social: A Mobilidade da População de Baixa Renda da Região Metropolitana de São Paulo e Trem Metropolitano. Dissertação de Mestrado, Universidade de São Paulo - USP, 2006

SILVEIRA, M. R.; COCCO, R. G. Transporte público, mobilidade e planejamento urbano: contradições essenciais. Estudos Avançados 27 (79), 2013.

ULIAN, F. Sistemas de Transportes Terrestres de passageiros em tempos de reestruturação produtiva na região metropolitana de São Paulo. Tese De Doutorado, Universidade de São Paulo - USP, 2008. 